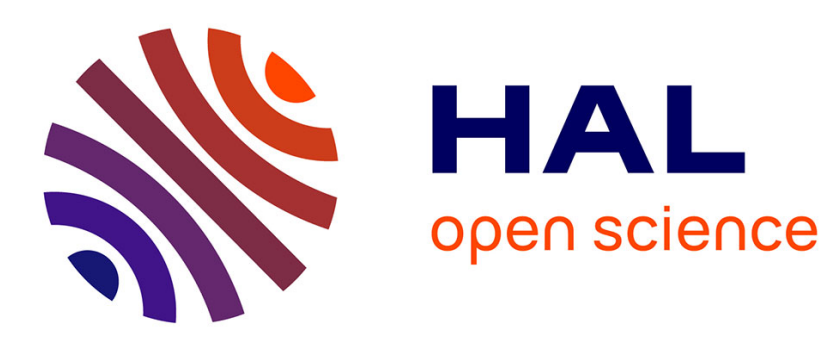

\title{
Spontaneous formation of two-dimensional wrinkles in poly(urethane-isocyanurate) rigid foam boards
}

\author{
Joël Reignier, Alexandru Sarbu, Vincent Barraud
}

\section{To cite this version:}

Joël Reignier, Alexandru Sarbu, Vincent Barraud. Spontaneous formation of two-dimensional wrinkles in poly(urethane-isocyanurate) rigid foam boards. Journal of Cellular Plastics, 2020, 56 (3), pp.297315. 10.1177/0021955X19864396 . hal-03295459

\section{HAL Id: hal-03295459 \\ https://hal.science/hal-03295459}

Submitted on 22 Jul 2021

HAL is a multi-disciplinary open access archive for the deposit and dissemination of scientific research documents, whether they are published or not. The documents may come from teaching and research institutions in France or abroad, or from public or private research centers.
L'archive ouverte pluridisciplinaire HAL, est destinée au dépôt et à la diffusion de documents scientifiques de niveau recherche, publiés ou non, émanant des établissements d'enseignement et de recherche français ou étrangers, des laboratoires publics ou privés. 


\title{
Spontaneous formation of two-dimensional wrinkles in poly(urethane- isocyanurate) rigid foam boards
}

\author{
Joël Reignier ${ }^{1}$, Alexandru Sarbu ${ }^{2}$ and Vincent Barraud ${ }^{2}$
}

1. INSA-Lyon, CNRS, UMR 5223 IMP, Univ Lyon, Villeurbanne, France

2. SOPREMA, Saint-Julien-du-Sault, France

\begin{abstract}
Processing low density poly(urethane-isocyanurate) rigid foam boards still remains challenging, especially for high thickness panels. In particular, subsequent shrinkage of the foam panel during cooling and cross-linking of the matrix creates in-plane compressive stresses in the facing that can be relieved by buckling with a relatively uniform wavelength of a few millimeters. An extensive study in the scientific literature documents the variety of wrinkling morphologies obtained when a thin film bonded on top of a soft substrate is compressed, and we proposed to apply this model in order to explain experimental observations of wrinkling in the case of a flexible facing bonded to a poly(urethane-isocyanurate) rigid foam. The wavelength, amplitude, and pattern of the waves were found to give information about the mismatch in Young's modulus as well as the level of compressive strain in the foam panel at the moment of wrinkling formation. A shore durometer (type 00) was systematically used to quickly probe the mechanical properties of the foam surface at various locations along the width of the insulation panel (after removal of the facing) and was found to be a valuable tool to explain the location of surface wrinkling and its evolution with time. Variations in mechanical properties of the foam surface were explained in terms of differences in cell orientation near the surface.
\end{abstract}

Keywords : Surface wrinkling, polyurethane, polyisocyanurate, foam, indentation, shore hardness, durometer, cell orientation, microstructure

Published in Journal of Cellular Plastics, vol. 56 (3), 297-315 (2020)

\section{Corresponding author:}

Joël Reignier, INSA-Lyon, CNRS, Univ Lyon, IMP@INSA, 17, Avenue Jean Capelle, Bâtiment Jules Verne, Villeurbanne 69621, France.

Email: joel.reignier@polymtl.ca 


\section{Introduction}

For over 20 years, poly(urethane-isocyanurate) rigid (PIR) foam panels have been extensively used for thermal insulation of buildings, mainly thanks to their better fire resistance with respect to more classical polyurethane rigid (PUR) foams. They are relatively easy to produce at an industrial scale, and their insulation capabilities will keep PIR foam demands high in the future. However, it is necessary to produce thicker insulation panels in order to save energy (cost reduction) and keep up with rising environmental requirements. Unfortunately, PIR foam panels (film-substrate composite) of thickness greater than a dozen of centimeters are often characterized by wrinkle patterns which spontaneously form on part of their surface (facing) within a few hours. In the end, these macroscopic surface defects can be considerable enough to suppose that the buyer might reject the merchandise or claim for a rebate. It is thus of critical importance to understand this phenomenon, to be able to predict its occurrence, and eventually to prevent its formation.

In order to understand the underlying principles leading to the formation of wrinkles, let us first consider an elastic thin film (or skin) which is assumed to be perfectly bonded to an infinitely thick and elastic substrate (or foundation), that is subject to a uniaxial lateral (in-plane) compression. When the nominal compressive strain $(\varepsilon)$ is relatively small, the complex structure is uniformly compressed but its main surface remains completely flat. However, once the strain exceeds a critical value, out-ofplane deformation takes place in order to accommodate the strain energy of the system. ${ }^{1}$ Two different classes of behavior are generally observed, namely buckling instabilities (wrinkling and delamination) and strain localizations (folding and creasing). We will focus our attention on the first case and more precisely on surface wrinkling i.e. when the film remains firmly attached to its foundation. In this case, the film adopts a sinusoidal wrinkling morphology perpendicular to the direction of load, as schematically depicted in Figure 1.

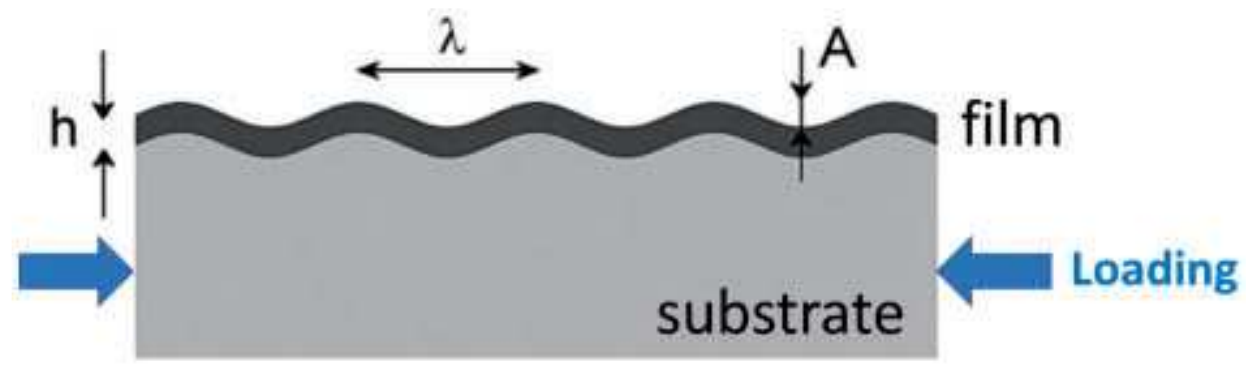

Figure 1. Schematic illustrating the geometry of wrinkles in an elastic thin film (thickness $h$ ) bonded to an infinitely thick elastic substrate. The wrinkles have a periodicity $\lambda$ and amplitude $A$.

The critical strain $\left(\varepsilon_{c}\right)$ at which the wrinkles appear is given by

$$
\varepsilon_{c}=\frac{1}{4}\left[3 \frac{\left(1-v_{f}^{2}\right) E_{s}}{\left(1-v_{s}^{2}\right) E_{f}}\right]^{2 / 3}
$$

where $v$ and $E$ are the Poisson's ratio and the Young's modulus of the rigid film (subscript $f$ ) and the elastic substrate (subscript $s$ ), respectively. ${ }^{2}$ In other words, the critical strain depends only on the material properties (the film and the substrate). The corresponding critical wavelength $\left(\lambda_{c}\right)$ of the wrinkle pattern is theoretically determined by 


$$
\lambda_{c}=2 \pi h\left[\frac{\left(1-v_{s}^{2}\right) E_{f}}{3\left(1-v_{f}^{2}\right) E_{s}}\right]^{1 / 3}
$$

where $h$ is the thickness of the rigid film. It is worth mentioning that these equations were derived by assuming that the shear traction and the tangential displacement at the film/substrate interface are negligible. However, when the material of the substrate is compressible (i.e. when $v_{s}<0.5$ ) which is typical for foam, the critical strain can be underestimated by up to $20 \%$ whereas the critical wavelength can be overestimated by up to $10 \% .{ }^{3}$ Nowadays, more complex models can be found in the literature, in particular when the substrate is not elastic but viscous or viscoelastic. ${ }^{4}$ As soon as the sinusoidal wrinkle appears, its amplitude $\left(A_{w}\right)$ is strain-dependent and increases relatively to the film thickness according to the following equation

$$
A_{w}=h\left[\frac{\epsilon}{\varepsilon_{c}}-1\right]^{1 / 2}
$$

Let us now describe a few examples of wrinkling surfaces that can be found in nature. For instance, the shrinking of the soft flesh occurring after drying (because of water removal) generates stress on the hard skin of some fruits, such as apples or plums, and may induce wrinkles with a wavelength in the order of a few millimeters. ${ }^{5}$ Mammalian skin, consisting of a thin-stiff epidermis coating a thicker and softer dermis, is also prone to buckle into wrinkles when laterally compressed. ${ }^{4}$ At a much larger scale (hundreds of kilometers), Volynskii and Bazhenov ${ }^{6}$ proposed to model the ocean floor relief formation (young oceanic crust/upper Earth's mantle complex structure) by the deformation of a polymer film with a rigid coating. At the level of industrial research, there are mainly two different areas of research. The first one encompasses all the works done on sandwich panels that are widely used in marine and aerospace engineering. They are prone to skin wrinkling when subjected to inplane compression or bending loads, leading to irreversible damage and possible material failure. ${ }^{7}$ In the second domain, researchers rather tried to take advantage of wrinkles formation in order to introduce topographical patterning onto surfaces at various length scales ranging from nanometers to tens of micrometers. Typically, thin metal (usually gold) films are deposited from the vapor phase on a thermally expanded polymer (usually polydimethylsiloxane, PDMS), and subsequent cooling of the polymer substrate creates compressive stress in the metal layer that is relieved by buckling/wrinkling. In addition, it was found that the waves can be controlled and oriented by relief structures in the surface of the polymer. ${ }^{1}$ More examples and applications can be found in the very attractive review proposed by Genzer and Groenewold. ${ }^{4}$ What is striking the most when we look at all these examples is the universality of the wrinkling phenomenon while the length scale spans over many orders of magnitude and the various materials are completely different. One could wonder if this model also applies in the case of PIR foam boards covered with flexible facings. Accordingly, we will first study the characteristics of the wrinkling pattern observed on PIR foam insulation panels and use the above relationships to obtain a measure of the modulus mismatch between the film and the substrate as well as the critical strain at the moment of wrinkle formation. Then the mechanical properties of the foam surface will be quantified at different points along the width of the foam panel by using a shore durometer (type 00) and the discrepancies explained in terms of difference in cellular morphology (aspect ratio and cell orientation) close to the surface. To the best of our knowledge, such in situ experimental investigations have never been described in the literature and may provide valuable information to prevent wrinkling formation of PIR foam insulation panels. 


\section{Experimental details}

\section{Materials}

The PIR foam insulation panels were produced at the SOPREMA's plant in Saint-Julien-du-Sault (France) and were obtained from a reactive foaming process with polymeric methylene diisocyanate (pMDI) and polyester polyol using isopentane as the physical blowing agent. Two different kinds of catalysts, namely tertiary amine and alkali metal carboxylate, were used to promote blowing and gelling reactions as well as the trimerization of pMDI. The exact details of the formulation are not given for confidential reasons. The density of the closed-cell foam specimens was around $32 \mathrm{~kg} / \mathrm{m}^{3}$ and was simply determined at room temperature by dividing the mass of a foamed cube by its volume. Three material directions can be defined on the basis of the foam rise direction and the orientation of the panel on the production line, as shown in Figure 2. TD (z-axis) represents the thickness direction (also called the foam rise direction), MD represents the machine direction and CMD ( $x$-axis) the crossmachine direction. These closed-cell foams follow a typical mechanical behavior of cellular solids ${ }^{8}$ with a linear stress-strain relation (typical Young's modulus, $E_{s} \approx 10 \mathrm{MPa}$, measured in TD) followed by a stress plateau (typical compressive stress, $\sigma_{s}^{*} \approx 200 \mathrm{kPa}$, measured in TD).

\section{Shore 00 durometer measurements}

A handheld shore durometer type 00 (Hildebrand model HD 3000) was used to determine the hardness of the foam without the facing. Basically, this durometer measures the penetration depth of a hemispherical indenter (or tip) in the material created by a given force on a standardized presser foot (see ASTM D 2240 standard for more details about the specific dimensions of the apparatus and the durometer spring characteristics ${ }^{9}$ ). In a typical experiment, a foam panel is taken from the production line right after the cross saw, and a $10-\mathrm{cm}$ wide band of facing is carefully removed on each side of the panel. Then the hardness of the foam surface $(\mathrm{HOO})$ is measured each $5 \mathrm{~cm}$ along the width ( $x$-axis) of the foam panel as quickly as possible in order to get a hardness profile. This distance was found to be sufficient to avoid edge or interference effects between indentations. ${ }^{9}$ The whole measurement process was usually accomplished in less than $10 \mathrm{~min}$. It is worth noting that several measurements have been done on the same panel in order to be sure that the shore hardness profile is not dependent on the way the facing is removed from the foam surface. Each measure (noted HOO) results in a dimensionless value between 0 and 100, with higher values indicating a harder material and thus a lower penetration depth (each durometer point indicated is equal to $0.025 \mathrm{~mm}$ of indenter travel). The time is measured from the moment when the liquid mixture is deposited on the laydown table $(t=0 \mathrm{~s})$. The repeatability of shore hardness measurements can be reasonably estimated at about \pm 1 . 


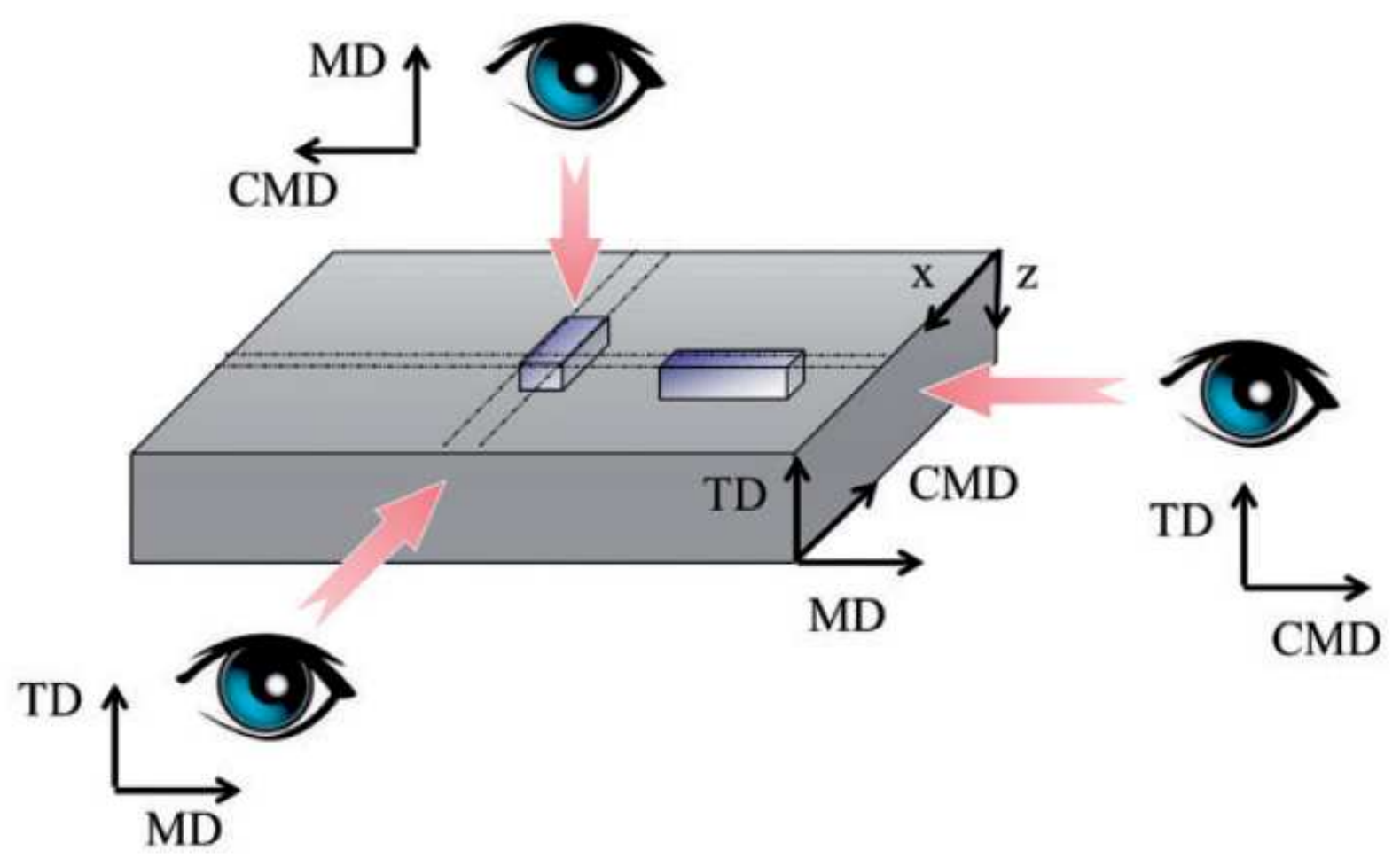

Figure 2. Definition of material directions and foam orientation used in the characterization of PIR foams.

\section{Morphology observation and image analysis}

Samples fractured in liquid nitrogen were coated with gold and observed using a scanning electron microscopy (SEM) (Hitachi, model S3500N) operated at a $15 \mathrm{kV}$ voltage. A semi-automatic method of image analysis (ImageJ software, U.S. National Institutes of Health) was used to quantify the cellular morphology. The aspect ratio of the cell is given by $R=a / b$, where $a$ and $b$ are the primary and secondary axis of the best fitting ellipse, respectively. The cell orientation is characterized by the angle $(\theta)$ between the primary axis and a line parallel to TD ( $z$-axis). An average number of about 70 cells was used to evaluate cell orientation and aspect ratio for each data point reported in Figure 9. Image was also used to convert the real-space image of the wrinkling pattern to Fourier space using fast Fourier transform (FFT) algorithms.

\section{Results and discussion}

Highlights of the periodicity of surface defects

The wrinkle morphology of the surface of PIR foam boards in low-angled light (to enhance the relief) reported in Figure 3(a) shows well-disordered patterns of peak (bright spots) and valleys (dark spots) on the surface (the terms labyrinth pattern is also used). The morphological similarity between this pattern and the microscopic-disordered structure observed by Bowden et al. ${ }^{1}$ in metal film/PDMS substrate upon biaxial contraction is amazing. This may suggest that the formation of wrinkles onto the surface of PIR foam panels could be described by equations (1) to (3). 
(a)

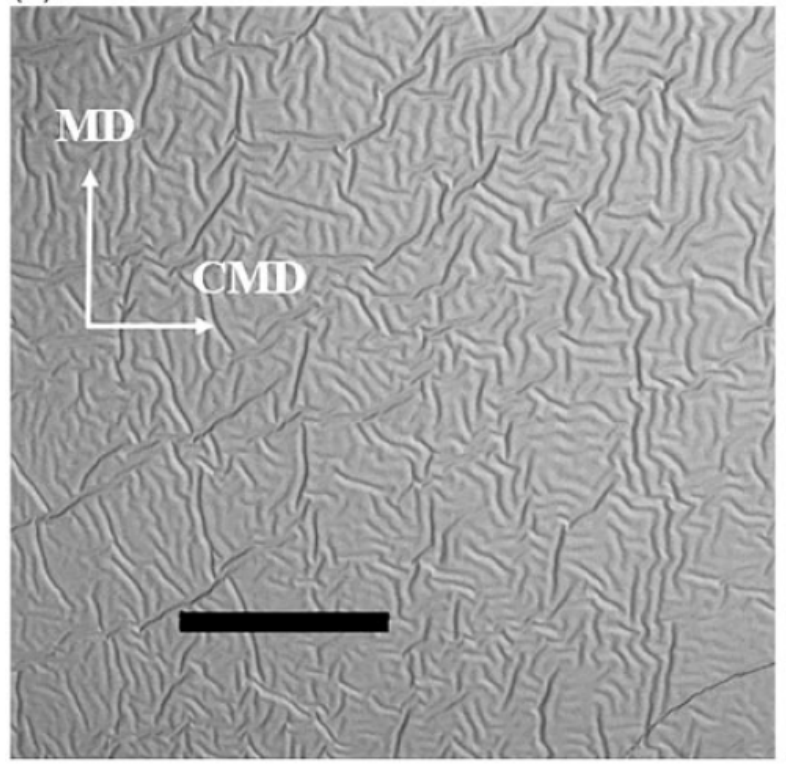

(b)

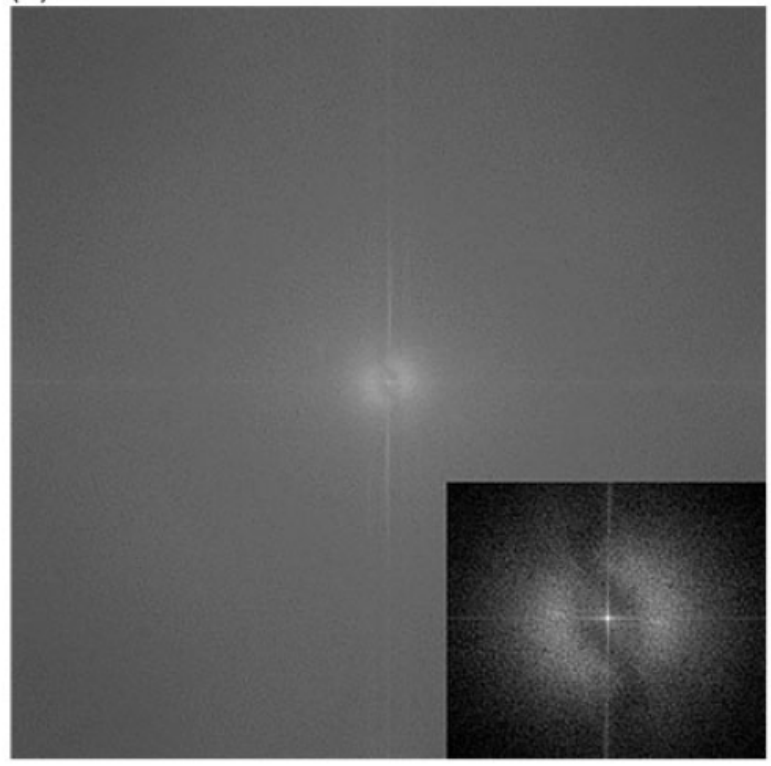

Figure 3. A description of the different steps leading to the characterization of the wavelength of the wrinkle pattern: (a) optical photograph showing a representative pattern of waves that formed on the face of the PIR panel during aging; (b) after conversion to Fourier space using FFT.

The inset is a zoom of the FFT image with higher contrast. The black bar in (a) represents a distance of $100 \mathrm{~mm}$.

To best quantify the wrinkling pattern, the resulting FFT is reported in Figure 3(b). It is characterized by an almost complete circular ring, thus indicating the directional randomness in the real-space pattern. However, a detailed analysis of the FFT image may reveal a tiny lack of periodicity in MD (lower density of points at the top end and bottom end of the circle) which may indicate that the in-plane strain is not isotropic. Huang et al. ${ }^{10}$ demonstrated by simulation that the symmetry can be broken whether the compressive strain is not the same in both directions, and wrinkles then begin to have some directional preference. In our case, the in-plane deformation of the complex structure results from an equilibrium between the shrinkage of the polymeric foam (matrix cross-linking and decreasing gas pressure during cooling) and the mechanical resistance to deformation provided by the facing. Since the cells of PIR foams tend to be elongated in the direction of foaming (TD) with an aspect ratio of about 1.5, foam panels can be considered as transversely isotropic from a mechanical point of view (the cells are stronger in the rise direction or TD) which also means that the mechanical properties of the foam substrate are very similar in $\mathrm{MD}$ and $\mathrm{CMD} .{ }^{11}$ In consequence, the use of a highly mechanically unbalanced facing may result in the formation of straight wrinkles aligned perpendicularly to the weakest direction of the facing (the resulting FFT image would be a series of peaks). Without going as far, facings used to prepare PIR foam panels usually contain a layer of Kraft paper with fibers preferentially aligned in MD. For instance, the tensile modulus ratio of the facing $\left(E_{\mathrm{MD}} / E_{\mathrm{CMD}}\right)$ shown in Figure 3 was found to be around 1.66 (according to the supplier) which may indicate that the facing would provide a slightly higher mechanical resistance to the shrinkage of the foam substrate in MD than in CMD. This tendency is reflected in the FFT image reported in Figure 3(b).

Interestingly, the dominant wavelength $\left(\lambda_{m}\right)$ of the wrinkling pattern can be directly measured on the FFT image and was found to be around $7.4 \mathrm{~mm}$, qualitatively consistent with our visual observations 
of the original image (Figure 3(a)). Obviously, the wrinkling wavelength is much greater than the film thickness ( $h=165 \mu \mathrm{m}$, according to the supplier), and hence the film modulus should be much greater than that of the substrate. More than a decade ago, Stafford et al. ${ }^{12}$ proposed to estimate the elastic modulus of very thin films (down to nanometer scale) by placing a thin polystyrene (PS) film of a given thickness and unknown modulus on top of an elastomeric substrate (PDMS) and by measuring the wrinkle wavelength when a compressive strain is mechanically applied to the specimen. Similarly, equation (2) can also be rewritten to estimate the Young modulus of the foam substrate (just underneath the facing) at the moment of wrinkle formation.

$$
E_{s}=\frac{E_{f}}{3} \frac{\left(1-v_{s}^{2}\right)}{\left(1-v_{f}^{2}\right)}\left(\frac{2 \pi h}{\lambda_{c}}\right)^{3}
$$

As a first approximation, one can neglect the effect of the difference in the Poisson coefficients between the foam and the facing, then equation (4) (with $\lambda_{c} \approx 7.4 \mathrm{~mm}, h=165 \mu \mathrm{m}$ and $E_{f} \approx 4 \mathrm{GPa}$ ) leads to $E_{s} \approx 3.6 \mathrm{MPa}$. This value is three orders of magnitude lower than the Young modulus of the facing $\left(E_{f} / E_{s} \approx 1100\right)$ which is completely in line with the established buckling mechanics (model). Obviously, the estimated value of $E_{s}$ at the time of wrinkling is smaller than the bulk value of compression modulus of PIR foam panel in TD $\left(E_{\mathrm{TD}} \approx 10 \mathrm{MPa}\right)$. This tends to demonstrate that the occurrence of wrinkles is caused by a particularly low compression modulus of the foam substrate on the surface.

Using the determination of $E_{s}$ and equation (1) to estimate the critical strain at which the wrinkles appear gives $\mathcal{E}_{c} \approx 0.5 \%$. This value is compatible with our results of shrinkage measurements (industrial internal evaluation). This tends to indicate that the in-plane shrinkage (MD and CMD) of PIR foam panels (measured at the level of the facing) linearly increases with the thickness of the foam panel from less than $0.1 \%$ (thickness $\approx 50 \mathrm{~mm}$ ) to about $0.7 \%$ (thickness $\approx 160 \mathrm{~mm}$ ). It is worth mentioning that the in-plane shrinkage of the foam panel without facing can reach values as high as $1.5 \%$ for the thickest panel $(160 \mathrm{~mm})$. Obviously, one of the best ways to prevent surface wrinkling of the facing is to ensure that the shrinkage (compressive strain) is lower than the critical deformation $\left(\varepsilon_{c}\right)$ and/or to increase $\varepsilon_{c}$ beyond the real shrinkage deformation. According to equation (1), $\varepsilon_{c}$ can be shifted to a higher value by increasing the Young modulus of the foam substrate $\left(E_{s}\right)$. This could be accomplished for instance by increasing the foam density. Conversely, it might appear tempting from equation (1) to reduce the Young modulus of the facing $\left(E_{f}\right)$ as it would also increase the Young modulus ratio $E_{s} / E_{f}$. But that overlooks the fact that the in-plane shrinkage of the foam substrate is strongly dependent on the mechanical properties of the facing: stronger facing leads to reduced shrinkage of the foam panel in MD and CMD. Unfortunately, this phenomenon is not taken into account in equation (1), and it is unclear which effect will dominate. Finally, it is worth noting that contrary to the classical case of a stiff film resting on an elastic thick substrate, the deformation of the foam substrate is irreversible and cannot return to its initial state because of the plastic deformation of the cellular structure near the surface, as shown in Figure 4.

\section{Relation between the hardness profile and the cellular morphology}

Generally speaking, the surface of the PIR foam panels is never entirely covered with wrinkles. Rather, the wrinkle patterns are distributed in the form of strips of variable widths which are parallel to MD. This observed inhomogeneity may indicate that the mechanical properties of the foam substrate (surface layer) may vary in magnitude along the width (CMD) of the foam panel. Conventional testing approaches used to determine mechanical properties of foam in compression conditions (Young 
modulus, buckling stress) are generally very time consuming and require well-defined sample shape and sizes which is incompatible with our desire to quickly (in a few minutes) compare the mechanical properties of the foam surface (fresh) at various locations. To circumvent those issues, it was decided to probe the local compression properties of the foam surface in the TD by using a type 00 shore durometer and this in spite of the fact that there is no relationship between shore hardness and any fundamental property such as Young modulus or compressive stress. Interestingly, the maximum projected surface area of the hemispherical indenter is around $4.5 \mathrm{~mm}^{2}$ which represents the surface area of slightly less than 100 cells and was found to be perfect for differentiation.

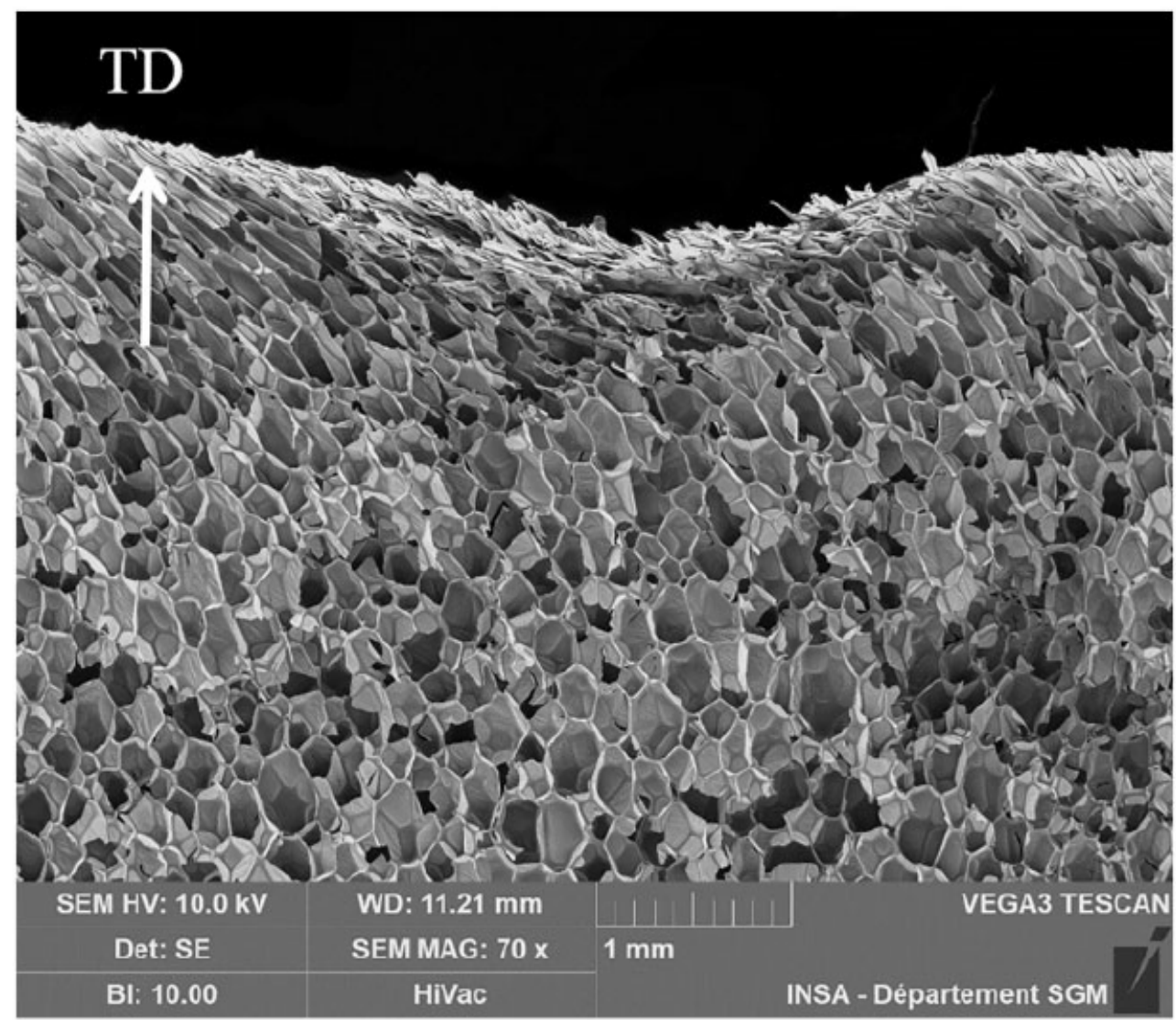

Figure 4. SEM micrograph of a section of the facing/foam panel showing the plastic deformation of the cellular structure underneath the facing and at the level of a valley (hollow).

Figure 5 shows an example of the hardness profile of a PIR foam panel (thickness $\approx 140 \mathrm{~mm}$ ) along the width (CMD or $x$-axis) after removal of the facing. Please note that the surface of the foam beyond $x \approx 100 \mathrm{~cm}$ was so irregular and grainy (overpacking) that it was not possible to give a credible measurement of the foam hardness. Apart from this damaged region, there is clearly a large variability of the foam hardness in TD. Interestingly, the wrinkling surface (between $x \approx 60 \mathrm{~cm}$ and $x \approx 80 \mathrm{~cm}$ ) seems to be associated with the area of lower hardness $\left(\mathrm{HOO}_{\min } \approx 66\right)$ whereas the surface free of defect (between $x \approx 10 \mathrm{~cm}$ and $x \approx 40 \mathrm{~cm}$ ) is characterized by the higher hardness value of the profile $\left(\mathrm{HOO}_{\max } \approx 76\right)$. Notice that 2D wrinkles appear in the region of hardness $(\mathrm{HOO})$ below a threshold of about 69 . Making the hypotheses that the chemical composition and cross-linking level of the matrix as well as the temperature are homogeneous on the whole surface, this may indicate that the cell orientation and/or aspect ratio of the cells near the surface are different. 


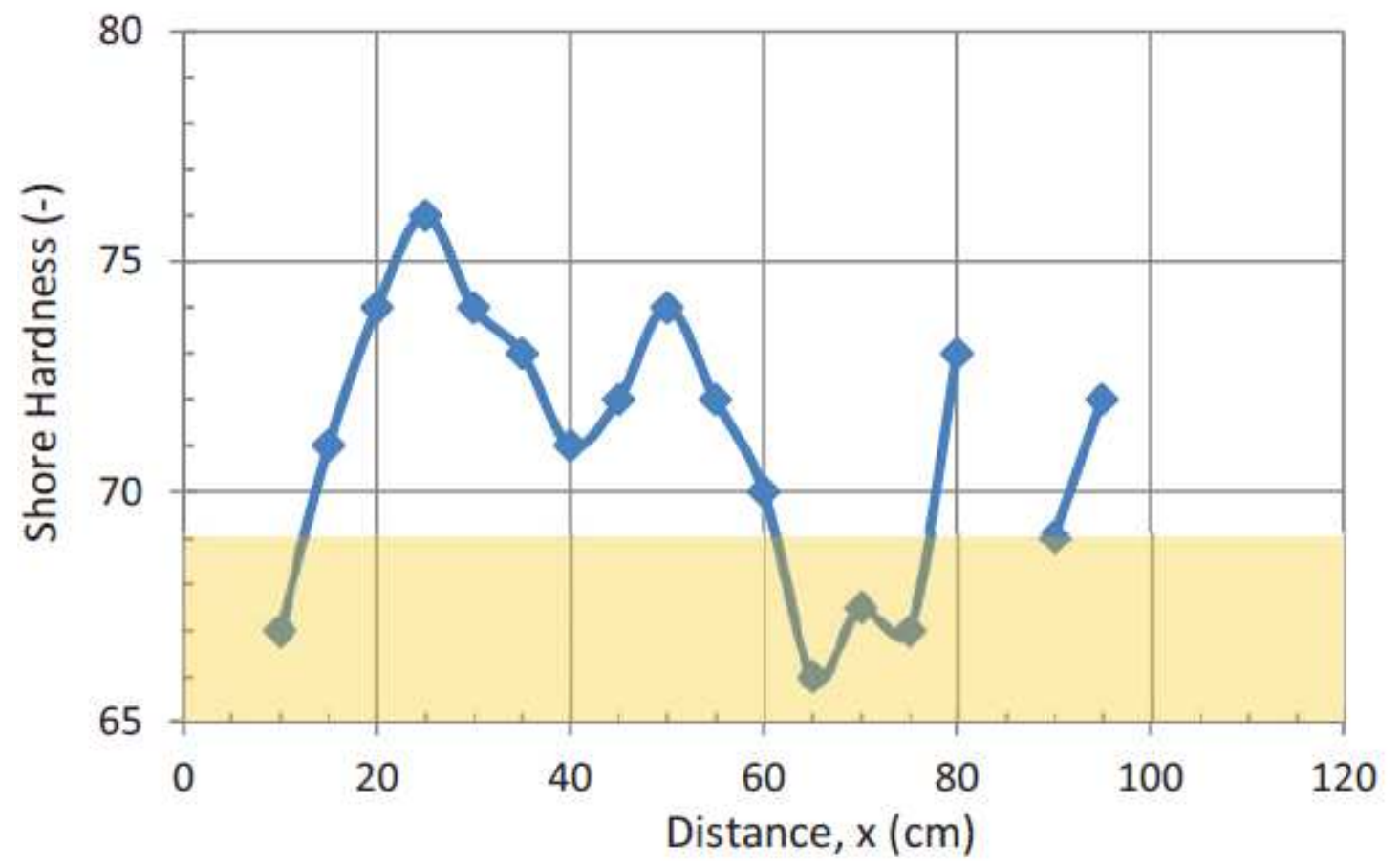

Figure 5. Evolution of the foam hardness (type 00 shore durometer) along the width (CMD or $x$-axis) of a PIR foam panels (thickness $\approx 140 \mathrm{~mm}$ ), after removal of the facing $(\mathrm{t} \approx 9 \mathrm{~min})$. The shaded area corresponds to a threshold of hardness $\mathrm{HOO} \approx 69$ below which 2D wrinkles appear.

To interpret these data, we thus proposed to compare the cellular morphology underneath the facing at two specific locations, namely $x \approx 25 \mathrm{~cm}$ ( $\mathrm{HOO} \approx 76$ ) and $x \approx 70 \mathrm{~cm}$ (HOO $\approx 67$ ). Figure 6 shows the SEM micrographs of the foam morphology when observed in TD (MD-CMD plane). Interestingly, the morphology appears completely different between the two regions. Cells associated with the highest hardness look smaller and more round in shape (Figure 6(a)) whereas cells corresponding to the lowest foam hardness are elongated in CMD and appear larger (Figure 6(b)).

(a)

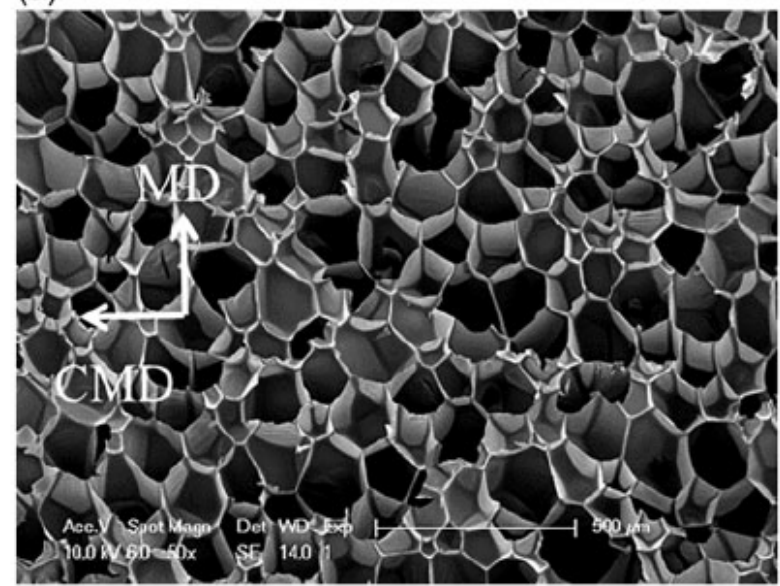

(b)

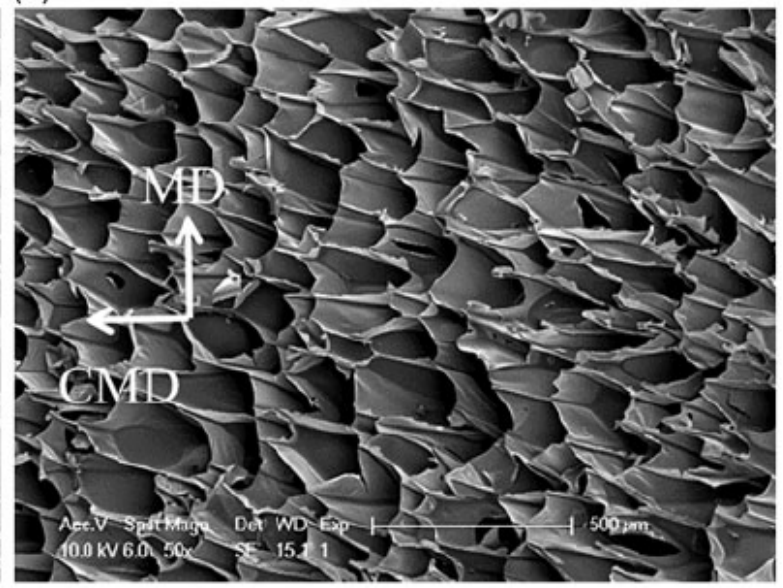

Figure 6. SEM micrographs of sections in PIR foams observed in TD (MD-CMD plane) for (a) H0O $\approx 76$ $(x \approx 25 \mathrm{~cm})$ and $(\mathrm{b}) \mathrm{HOO} \approx 67(x \approx 70 \mathrm{~cm})$. 
To have a comprehensive vision of cell orientation, the morphology of the foam corresponding to the shore hardness $\mathrm{HOO} \approx 76$ is depicted in Figure 7 (TD-MD and TD-CMD planes) at various depths from the surface. The upper end of Figure 7 (a) and (b) corresponds to the foam surface just underneath the facing $(z \approx 0)$. In a general manner, the cellular morphology is relatively homogenous with cells slightly elongated in TD, and it does not seem to depend on the depth. By contrast, the various foam morphologies corresponding to the shore hardness $\mathrm{HOO} \approx 67$ depicted in Figure 8 clearly indicate that the cell aspect ratio and orientation differ considerably between the top layer and the layer below $(z \approx 4-6 \mathrm{~mm}$ ). Indeed, cells close to the surface (first millimeter) seem to have been stretched in CMD and thus appear flattened in TD. Discussion about the origins of cell orientation inside the conveyor of the production line is complex and fascinating but beyond the scope of this paper. It could nevertheless be mentioned that cell orientation near the surface is linked to the fact that along the $x$-axis (CMD), the expanding foam does not touch the top part of the conveyor at the same time because of small variation of the liquid film thickness (before expansion) as well differences in foam age.

(a)

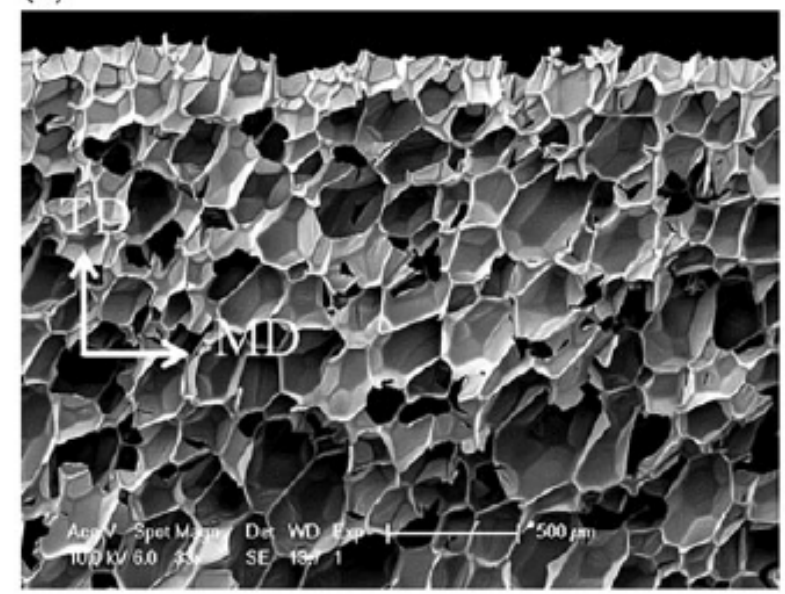

(c)

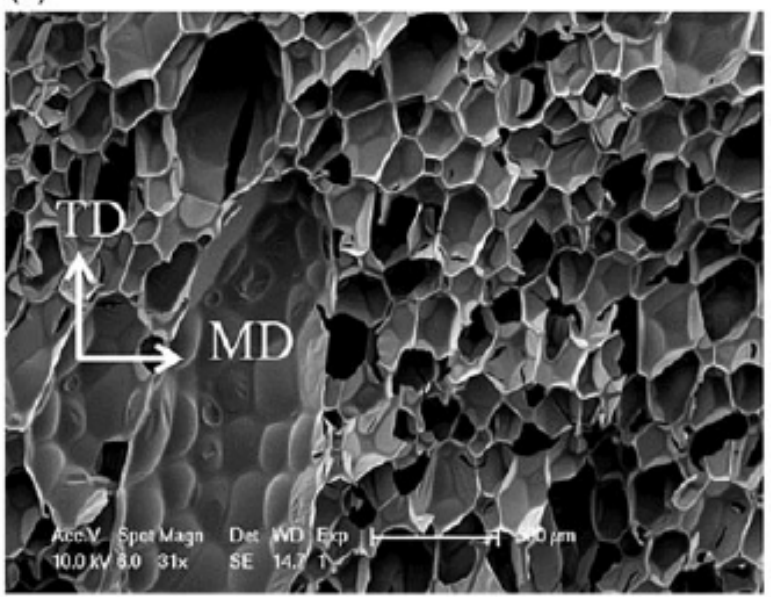

(b)

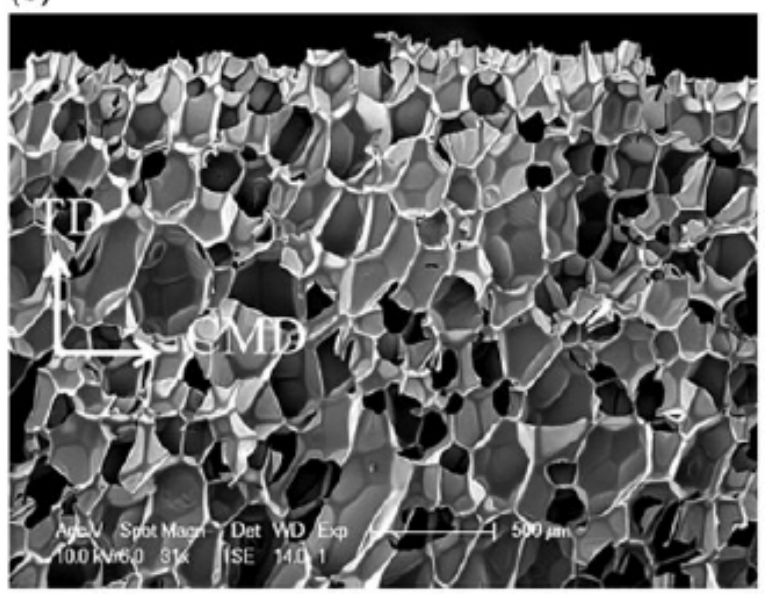

(d)

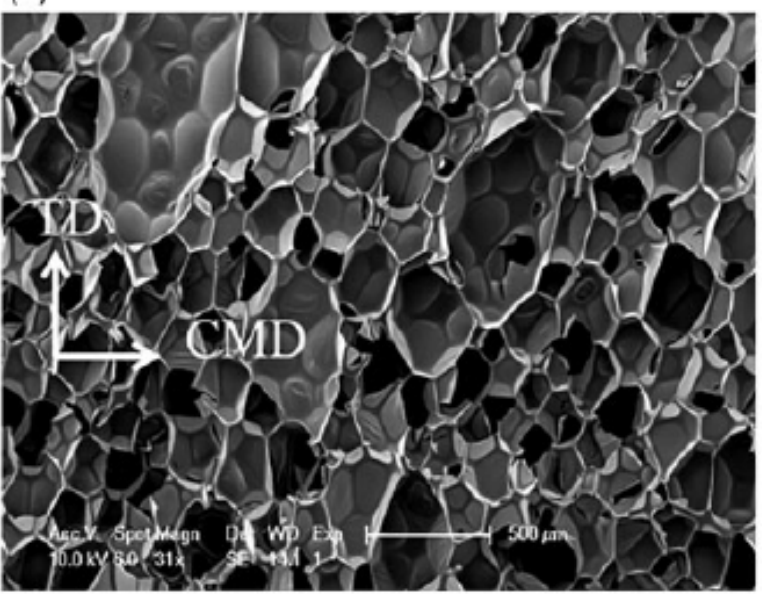

Figure 7. SEM micrographs of sections in foams observed for $\mathrm{HOO} \approx 76(x \approx 25 \mathrm{~cm})$ in $(\mathrm{a}, \mathrm{c})$ the TDMD plane and (b, d) the TD-CMD plane. The foam depth range is $z \approx 0-2 \mathrm{~mm}$ for $(a, b)$ and $z \approx 4-6 \mathrm{~mm}$ for (c, d). 
(a)

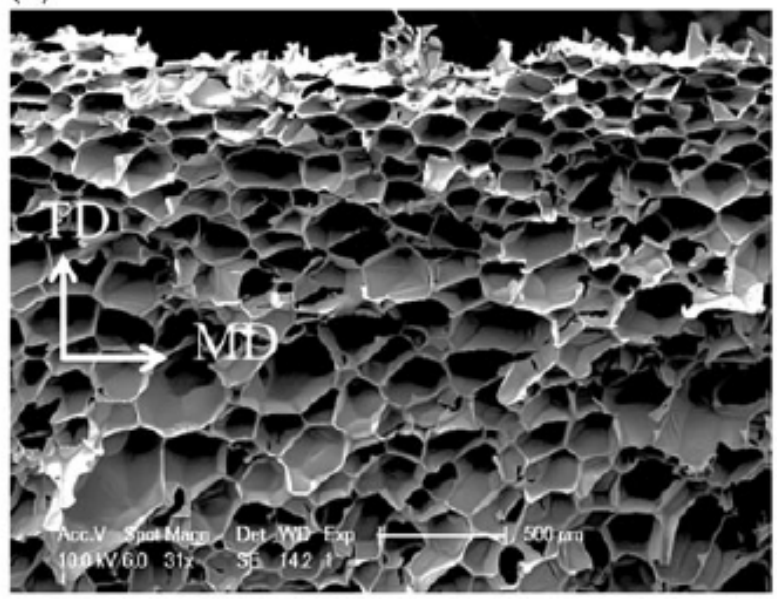

(c)

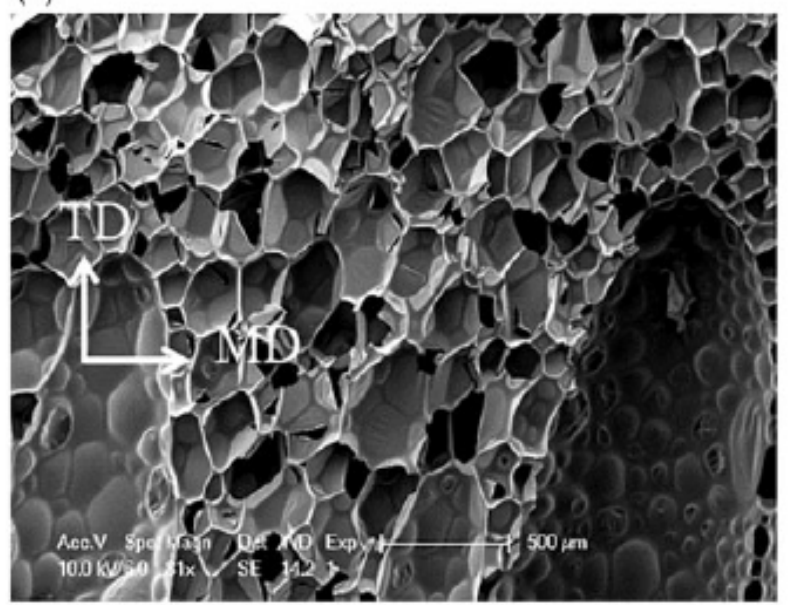

(b)

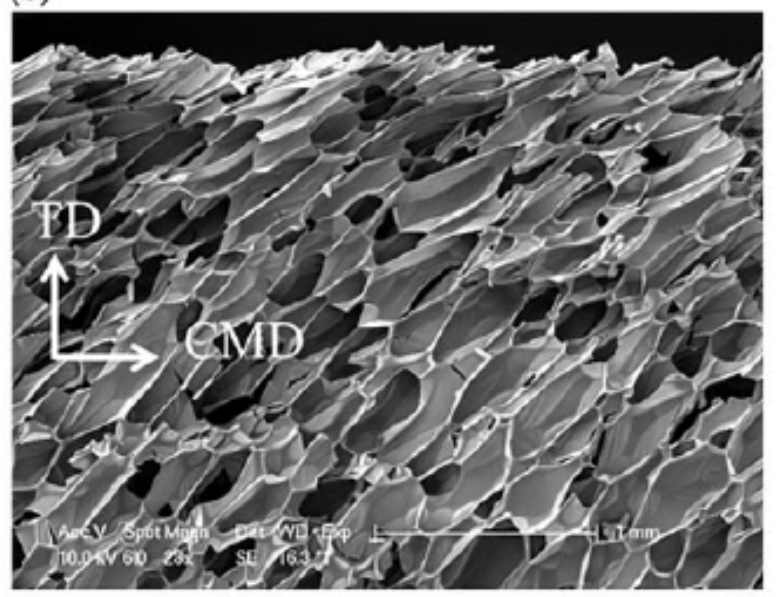

(d)

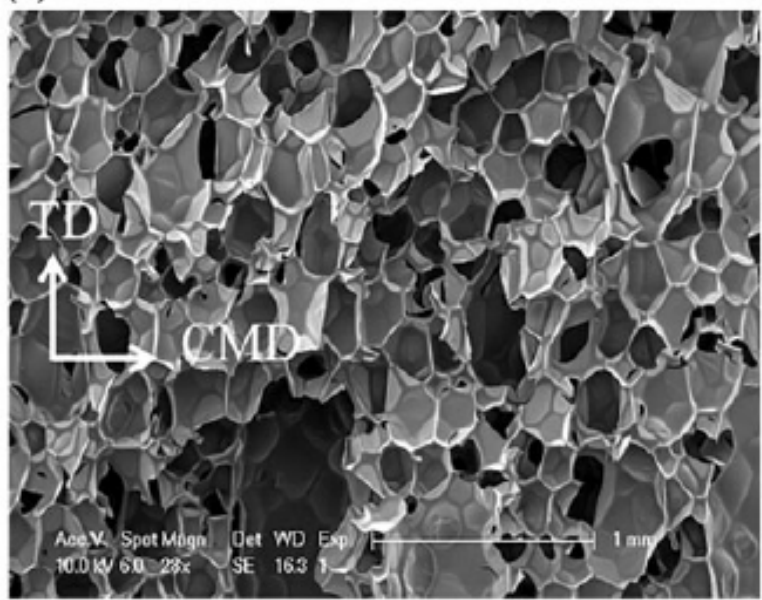

Figure 8. SEM micrographs of sections in foams observed for $\mathrm{HOO} \approx 67(x \approx 70 \mathrm{~cm})$ in $(\mathrm{a}, \mathrm{c})$ the TDMD plane and $(b, d)$ the TD-CMD plane. The foam depth range is $z \approx 0-2 \mathrm{~mm}$ for $(a, b)$ and $z \approx 4-6 \mathrm{~mm}$ for (c, d).

To complete this visual description, quantitative information about cell orientation and cell aspect ratio are given as a function of depth ( $z$-axis) in Figure 9. Each point corresponds to the average value obtained for a foam layer having a thickness of about $2 \mathrm{~mm}$ (thus there are three layers between $z \approx 0 \mathrm{~mm}$ and $z \approx 6 \mathrm{~mm}$ ). In the region of high hardness ( $\mathrm{HOO} \approx 76$ ), cells are slightly elongated $(R \approx 1.5$ ) on the surface as well as deeper inside the foam. In addition, the average orientation of the cells is close to the vertical $\left(\theta \approx 20^{\circ}\right)$ in the TD-CMD plane. These morphological characteristics of the cellular structure with higher extension of the cells in the rise direction (TD) are typical of PUR and PIR foams. ${ }^{13-}$ ${ }^{15}$ For instance, Rhida and Shim ${ }^{14}$ have shown for PUR foams that the cell shape factor increases from $R=1.7$ for foam density $\rho_{f} \approx 35.2 \mathrm{~kg} / \mathrm{m}^{3}$ to about $R=2.5$ for $\rho_{f} \approx 23.3 \mathrm{~kg} / \mathrm{m}^{3}$. This geometrical anisotropy of cells usually translates into anisotropy of the mechanical properties with higher stiffness in the rise direction.

Interestingly, in our case, the major axis of the cells is moving away a bit from the vertical (TD) in the TD-MD plane, and this phenomenon is more pronounced close to the surface $\left(\theta_{\max } \approx 42^{\circ}\right)$. It is thus expected to reach even higher shore hardness values whether the cells were perfectly oriented parallel to TD. In the region of low hardness ( $\mathrm{HOO} \approx 67$ ), cells are far more elongated with an aspect ratio 
reaching an average value as high as $R \approx 2.7$ (TD-CMD plane) in the first $2 \mathrm{~mm}$ thick foam layer. Such stretching of the cells tends to level off deeper in the foam with an $R$ value dropping down to less than 1.5 beyond a depth of $4 \mathrm{~mm}$ under the surface. However, the most damaging effect is not the higher $R$ value itself but the fact that cells close to the surface are mostly elongated in MD and CMD rather than in $\operatorname{TD}\left(\theta_{\max } \approx 73^{\circ}\right)$. Everything becomes similar to previous observations ( $\mathrm{HOO} \approx 76$ ) deeper in the foam with less elongated cells which are generally oriented parallel to TD ( $z$-axis).
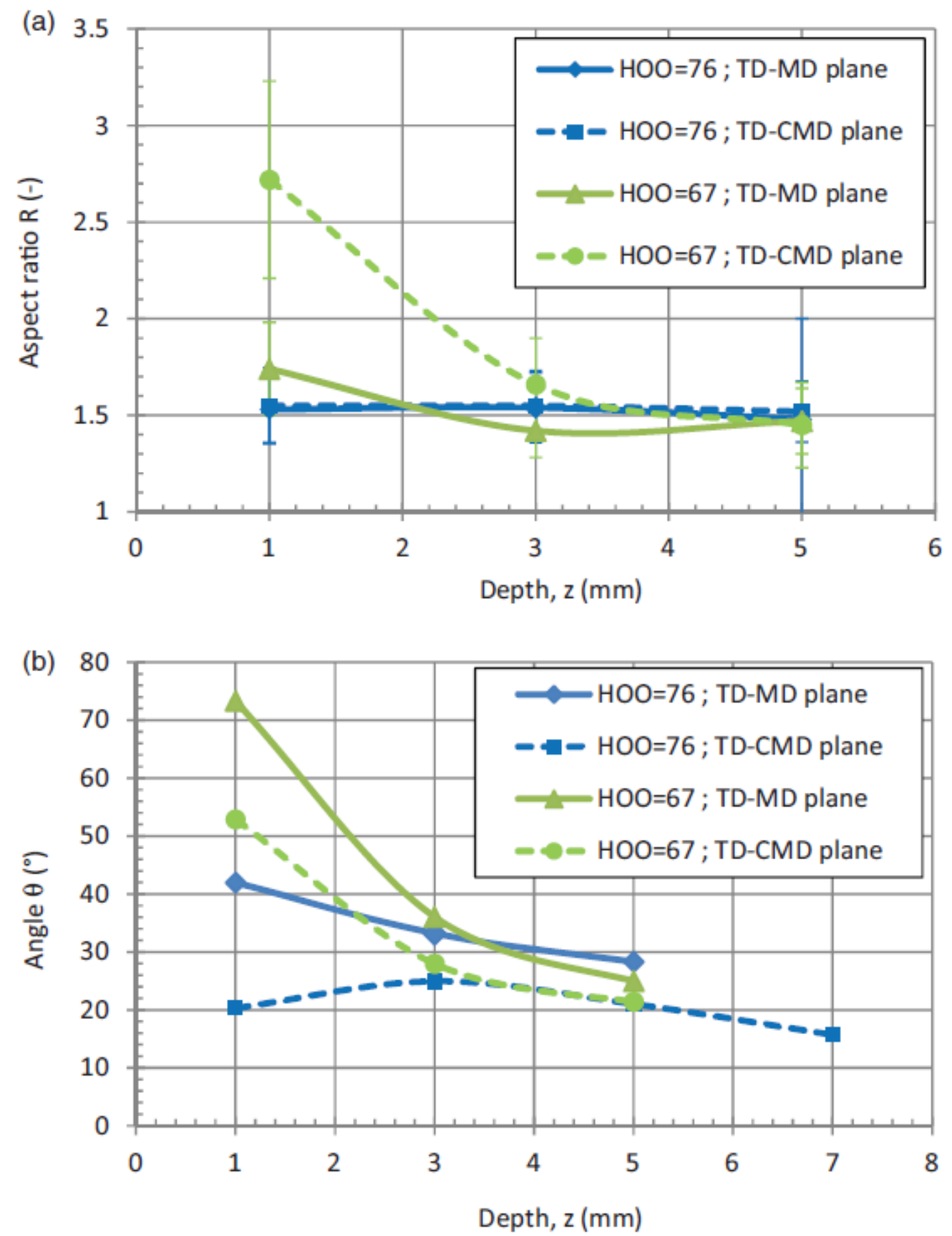

Figure 9. Evolution of (a) the aspect ratio $(R=a / b)$ and (b) the orientation angle $\theta$ as a function of depth (z-axis) for the two particular regions corresponding to a shore 00 hardness of H0O $\approx 76$ $(x \approx 25 \mathrm{~cm})$ and $\mathrm{HOO} \approx 67(\mathrm{x} \approx 70 \mathrm{~cm})$.

The results presented herein seem to indicate that the difference in shore hardness of the foam surface originates from the various cellular morphologies observed in the first few millimeters of the foam 
substrate. Indeed, Huber and Gibson ${ }^{11}$ have demonstrated both theoretically and experimentally that the mechanical properties of anisotropic cellular materials depend on the direction in which they are measured. In particular, the Young modulus anisotropy ratio given by

$$
\frac{E_{L}}{E_{T}}=\frac{2 R^{2}}{1+(1 / R)^{3}}+(1-\varphi) \frac{2 R}{1+(1 / R)}
$$

and the uniaxial yield stress (or plastic collapse) ratio defined by

$$
\frac{\sigma_{L}^{*}}{\sigma_{T}^{*}}=\frac{2 R}{1+1 / R}
$$

were found to describe well the mechanical properties of PUR and PIR foams. Subscripts $L$ and $T$ refer to the longitudinal and transverse directions, respectively, while $\varphi$ is the fraction of solid in the cell edges. In other words, the mechanical properties of the foam should be higher in the rise direction with increasing $R$. But it also means that the mechanical properties are lower in the transverse direction and to a lesser extent in any direction different from the longitudinal direction of the cells. According to equation (1), reducing the compression modulus of the substrate $\left(E_{s}\right)$ should lower the critical strain above which wrinkling should occur. In this context, wrinkling surface is more prone to occur in the region of lower shore hardness associated with cells strongly oriented in the MD-CMD plane rather than in the region of higher shore hardness characterized by cells oriented parallel to TD.

\section{Evolution of wrinkling surface with time}

The above analysis focuses on the relation between the shore hardness and the cellular morphology of the substrate near the surface (thin outer layer). We further studied the formation and evolution of wrinkles as a function of ageing time (at ambient pressure and temperature) and its relation to the shore hardness profile (measured at $t \approx 12 \mathrm{~min}$ ) as shown on Figure 10 for another PIR foam panel (thickness $\approx 140 \mathrm{~mm}$ ). In qualitative terms, the height of the colored strips corresponds to the amplitude of the wrinkles. The foam panel remains free of surface defects before a little bit more than $t \approx 30 \mathrm{~min}$. The first wrinkles appear between $x \approx 40 \mathrm{~cm}$ and $x \approx 60 \mathrm{~cm}$ (center of the panel) at $t \approx 37 \mathrm{~min}$. Interestingly, this area corresponds to the lowest shore hardness (H0O <68). After $t \approx 80 \mathrm{~min}$, this area has grown in amplitude and now expands from $x \approx 35 \mathrm{~cm}$ to $x \approx 80 \mathrm{~cm}$. In addition, low amplitude wrinkles can now be observed on the surface of the right edge of the panel $(x \approx 110 \mathrm{~cm})$. The corresponding shore hardness is slightly higher, typically in the order of 68-70. After more than $3 \mathrm{~h}$ of ageing $(t \approx 224 \mathrm{~min}$ ), the wrinkle area has been extended to the whole panel width but with different amplitudes. The wrinkles have now reached the surfaces corresponding to the highest values of shore hardness ( $\mathrm{HOO} \approx 72-74$ ). Eventually, the amplitude of the wrinkles tends to increase slightly up to an ageing time of about one day $(t \approx 1340 \mathrm{~min})$ to give the final image reported in Figure 11. According to equation (3), increasing compression strain (e) should generate a continuous increase of the amplitude of the wrinkles. As a result, the freeze in the morphology of the wrinkles after about one day may indicate that the shrinkage of the foam panel has ended. 


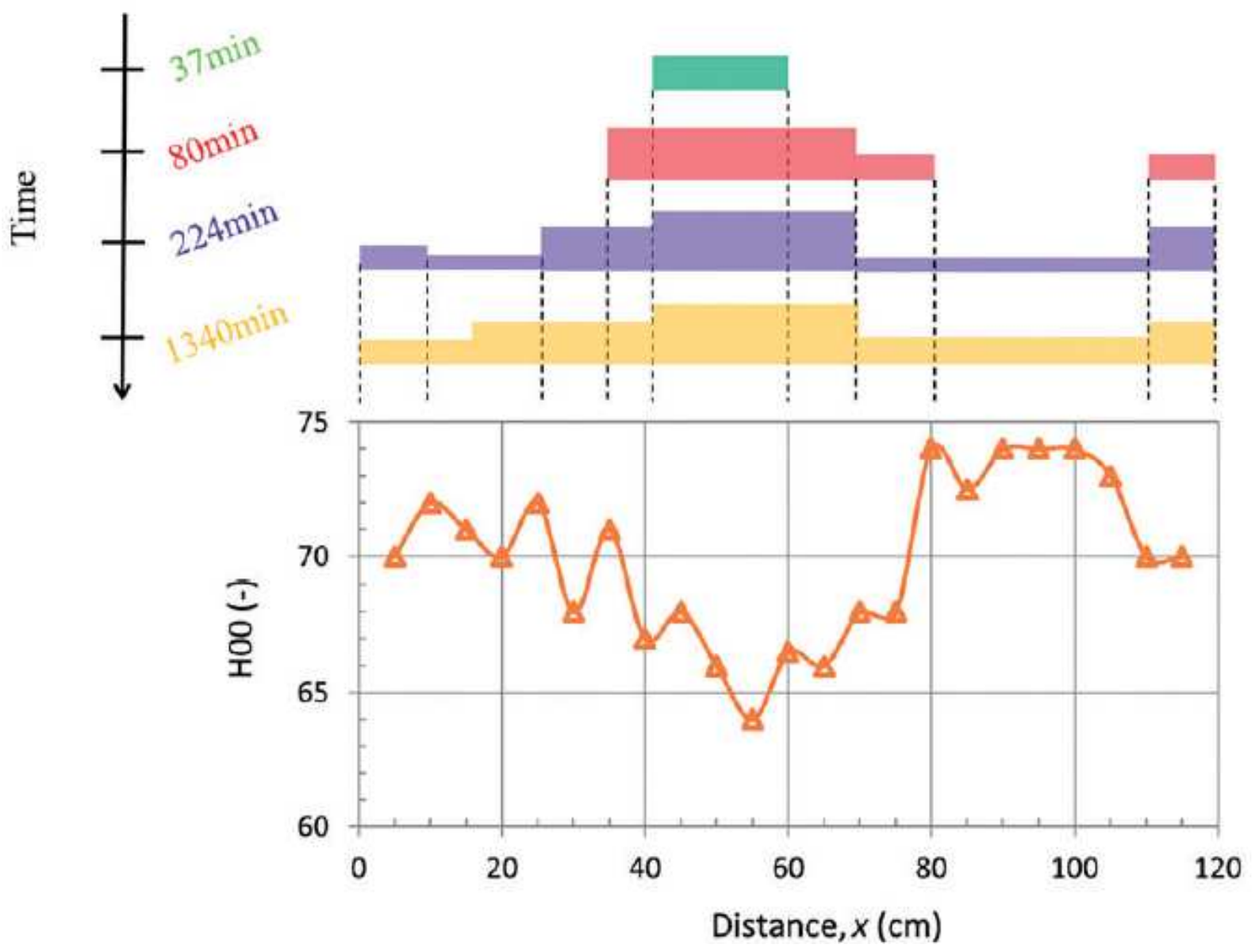

Figure 10. Evolution of the wrinkles characteristics (span and amplitude) covering the surface of the PIR foam panel (thickness $\approx 140 \mathrm{~mm}$ ) as a function of time (top) and shore hardness (HOO) variation along the width of the foam surface (measured at $t \approx 12 \mathrm{~min}$ ) after removal of the facing (bottom).

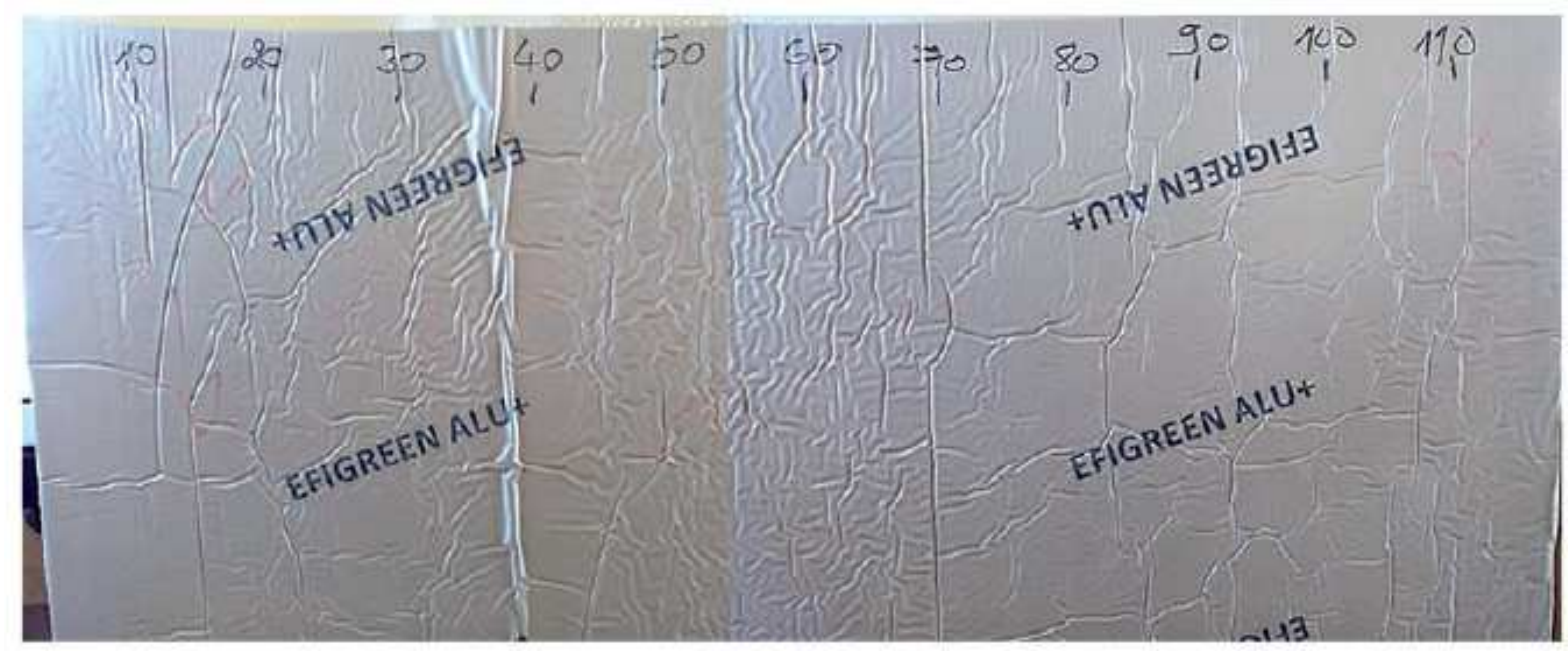

Figure 11. Photograph showing the final wrinkling pattern along the whole width of the PIR foam panel. The numbers represent the distance, $x$ (in $\mathrm{cm}$ ), from the left edge of the foam panel and is used for the purpose of comparison with the hardness profile shown in Figure 10. 
It is worthwhile to note that Brau et al. ${ }^{16}$ reported a continuous shift to lower wavelength as compressive strain increases $\left(\lambda=\lambda_{0}(1-\delta)\right.$ for $\left.\varepsilon>\varepsilon_{c}\right)$ but the change in wavelength was not noticeable in our case because of small compression levels $(\varepsilon<1 \%)$. More importantly, the results reported in Figure 10 indicate that the onset time of wrinkle formation is not the same along the width of the panel ( $x$-axis) which implies that the compressive strain for wrinkling $\left(\varepsilon_{c}\right)$ may vary a lot along the $x$-axis. Clearly, increasing the hardness of the foam surface allows to postpone the onset of wrinkle formation to higher compressive strain.

In the best-case scenario, the hardness of the foam may be high enough to verify that the critical compressive strain is higher than the maximum strain occurring during the ageing of the foam panel $\left(\varepsilon_{c}>\mathcal{E}\right.$ ), which may be the case when the shrinkage is reduced (lower foam thickness and/or stiffer facing) and/or when the cells are perfectly aligned in TD in the surface layer. From a practical point of view, it is worth noting that we can consider the use of hardness profile to predict the occurrence of wrinkles.

For the sake of completeness, it should be noted that more complex patterns can be involved as shown in Figure 11 near $x \approx 35 \mathrm{~cm}$ where delamination clearly occurred. According to Mei et al.,, ${ }^{17}$ buckle delamination is intuitively associated with relatively stiff substrates and usually needs high critical stress for wrinkling. However, the presence of interfacial defects can reduce the substrate constraint, leading to partial delamination of the film. The delaminated portion of the film buckles upward, which in turn drives the growth of delamination through interfacial fracture. In the case of a metallic film deposited on a polycarbonate substrate, Boijoux et al. ${ }^{18}$ compared the shape of the buckling structures with a "Mexican hat" and used the nanometer scale depression at both edges of the buckling structure to extract the Young's modulus mismatch between the film and the substrate. Ebata et al. ${ }^{19}$ demonstrated that a PS film attached to a PDMS substrate will change from a wrinkled to a delaminated state when the strain is greater than the critical strain for delamination (ed) which scales as

$$
\varepsilon_{d} \sim\left(\frac{G_{C}}{E_{s} h}\right)^{3 / 5}\left(\frac{E_{s}}{E_{f}}\right)^{1 / 5}
$$

where $G_{c}$ is the critical energy for separating the interface into two surfaces. Obviously, $\varepsilon_{d}$ increases with $G_{c}$ but more importantly, $\varepsilon_{d}$ is inversely proportional with the thickness of the film to the power of $3 / 5$, which means that decreasing the film thickness should allow to postpone delamination to higher compressive strain.

Eventually, it is worth noting that Nolte et al. ${ }^{20}$ developed a predictive model to determine whether a system will initially display surface wrinkling or buckle delamination. Accordingly, wrinkling is the preferred buckling instability mode when the film is well-adhered (high $G_{c}$ ) to a substrate that has a significantly lower modulus and when it can be relatively easy to bent (low film modulus and small film thickness). Fortunately, this is typically the case for facing/PIR foam system which usually prevents the formation of buckle delamination. 


\section{Concluding remarks}

In summary, we provided a comprehensive description of the spontaneous generation of twodimensional wrinkles in PIR insulation panels generated by biaxial in-plane shrinkage (during ageing at room temperature). Showing the similarity of the wrinkling pattern of foam board facing with that reported for rigid film resting on a soft elastic substrate, the modulus-dependent wavelength of the buckling instability was interpreted using established equations and allowed us to give a rough estimate of the Young modulus of the foam substrate at the start of wrinkle formation ( $E_{s} \approx 3.6 \mathrm{MPa}$ ) as well as of the critical strain $\left(\varepsilon_{c} \approx 0.5 \%\right)$. However, one major difference compared with more classical film/substrate system found in the literature is that the compressive strain (in-plane shrinkage) of the foam substrate is strongly dependent on the mechanical properties of the facing which may interfere with the conclusions based solely on these equations.

A durometer shore (type 00 ) was found to be a very powerful tool to probe the hardness of the flat surface of low density $\left(\rho_{f} \approx 32 \mathrm{~kg} / \mathrm{m}^{3}\right)$ PIR foam (after facing removal). In particular, the variation of the shore hardness along the width of the foam panel allowed to clearly identify and quantify soft and hard regions.

Then, we clearly established the link between the cellular morphology under the surface (a few millimeters) and the level of shore hardness. At higher $\mathrm{HOO}$ values, cells are preferentially oriented in the rise direction (TD) whereas cells are mostly elongated in MD and/or CMD (in-plane) for lower H0O values. Obviously, wrinkling surfaces are more prone to occur in the regions of low hardness. Monitoring of temporal evolution of wrinkling clearly demonstrated that sinusoidal deformations hierarchically appear: first, the region of lower shore hardness followed by the region of higher stiffness while the amplitude of the wave on already formed wrinkles increases with time. The above results suggest that it will be possible to predict wrinkling formation for a given facing and foam thickness if the shore hardness falls down below a critical threshold.

\section{Declaration of conflicting interests}

The author(s) declared no potential conflicts of interest with respect to the research, authorship, and/or publication of this article.

\section{Funding}

The author(s) received financial support from SOPREMA for the research, authorship, and/or publication of this article.

\section{References}

1. Bowden N, Brittain S, Evans AG, et al. Spontaneous formation of ordered structures in thin films of metals supported on an elastomeric polymer. Nature 1998; 393: 146-149.

2. Huang R, Stafford CM and Vogt BD. Effect of surface properties on wrinkling of ultrathin films. J Aerosp Eng 2007; 20: 38-44. 
3. Mei $\mathrm{H}$, Landis $\mathrm{CM}$ and Huang R. Concomitant wrinkling and buckle-delamination of elastic thin films on compliant substrates. Mech Mater 2011; 43: 627-642.

4. Genzer J and Groenewold J. Soft matter with hard skin: from skin wrinkles to templating and material characterization. Soft Matter 2006; 2: 310-323.

5. Cerda E and Mahadevan L. Geometry and physics of wrinkling. Phys Rev Lett 2003; 90: 074302074314

6. Volynskii AL and Bazhenov SL. Can deformation of a polymer film with a rigid coating model geophysical processes? Eur Phys J E 2007; 24: 317-324.

7. Fagerberg $L$ and Zenkert D. Imperfection-induced wrinkling material failure in sandwich panels. $J$ Sandwich Struct Mater 2005; 7: 195-219.

8. Gibson LJ and Ashby MF. Cellular solids: structure and properties. 2nd ed. Cambridge: Cambridge University Press, 1997

9. ASTM International D 2240-05. Standard Test Method for Rubber Property- Durometer Hardness. 100 Barr Harbor Drive, PO Box C700, West Conshohocken, PA 19428-2959, USA, 2005.

10. Huang $Z Y$, Hong $W$ and Suo $Z$. Nonlinear analyses of wrinkles in a film bonded to a compliant substrate. J Mech Phys Solids 2005; 53: 2101-2118.

11. Huber AT and Gibson LJ. Anisotropy of foams. J Mater Sci 1988; 23: 3031-3040.

12. Stafford CM, Vogt BD, Harrison C, et al. Elastic moduli of ultrathin amorphous polymer films. Macromolecules 2006; 39: 5095-5099.

13. Dawson JR and Shortall JB. The microstructure of rigid polyurethane foams. J Mater Sci 1982; 17: 220-224.

14. Ridha $M$ and Shim V. Microstructure and tensile mechanical properties of anisotropic rigid polyurethane foam. Exp Mech 2008; 48: 763-776.

15. Andersons J, Kirpluks M, Stiebra L, et al. Anisotropy of the stiffness and strength of rigid low-density closed-cell polyisocyanurate foams. Mater Des 2016; 92: 836-845.

16. Brau F, Vandeparre $\mathrm{H}$, Sabbah A, et al. Multiple-length-scale elastic instability mimics parametric resonance of nonlinear oscillators. Nat Phys 2011; 7: 56-60.

17. Mei H, Huang R, Chung JY, et al. Buckling modes of elastic thin films on elastic substrates. Appl Phys Lett 2007; 90: 151902-151902-3.

18. Boijoux R, Parry G and Coupeau C. Buckle depression as a signature of Young's modulus mismatch between a film and its substrate. Thin Solid Film 2018; 645: 379-382.

19. Ebata Y, Croll AB and Crosby AJ. Wrinkling and strain localizations in polymer thin films. Soft Matter 2012; 8: 9086-9091.

20. Nolte AJ, Chung JY, Davis CS, et al. Wrinkling-to-delamination transition in thin polymer films on compliant substrates. Soft Matter 2017; 13: 7930-7937. 